\title{
Conscientiousness Moderates the Influence of a Help-Eliciting Prime on Prosocial Behavior
}

\author{
Rhonda Swickert, Branden Abushanab, Hannah Bise, Rebecca Szer \\ Department of Psychology, College of Charleston, Charleston, SC, USA \\ Email: swickertr@cofc.edu
}

Received 11 August 2014; revised 5 September 2014; accepted 2 October 2014

Copyright @ 2014 by authors and Scientific Research Publishing Inc.

This work is licensed under the Creative Commons Attribution International License (CC BY). http://creativecommons.org/licenses/by/4.0/

(c) (i) Open Access

\section{Abstract}

This study tested whether personality influenced the effect of a help-eliciting prime. Participants $(N=203)$ attended two experimental sessions. In the first session, Conscientiousness was measured along with several control variables. Participants returned for a second session where they were randomly assigned to a help-eliciting prime or a Control prime. After completing the written prime exercise, participants were asked to respond to a helping scenario. Textual analyses showed that written responses to the help-eliciting prime differed across level of Conscientiousness, with individuals high in Conscientiousness writing more often about one's moral obligation to help. An ANCOVA analysis revealed a significant main effect for Conscientiousness, as well as a significant interaction effect between Conscientiousness and the Prime. Individuals scoring higher in Conscientiousness were more likely to provide assistance, and this was particularly true if they were in the help-eliciting prime condition. Our results are supportive of an interactional model where one must consider both personality and situational factors to successfully understand and predict helping responses.

\section{Keywords}

Interactionism, Conscientiousness, Priming, Helping, Prosocial Behavior, Social Behavior

\section{Introduction}

Theorists in the personality trait literature have long recognized that the expression of a personality trait can be influenced by situational factors, a process termed "interactionism” (Ekehammer, 1974; Endler \& Magnusson, 1976). While most researchers who study personality traits endorse this position, in practice most of the pub- 
lished work in the field is still conducted in isolation from a true manipulation of situational factors. One viable way to examine how situational forces might interact with personality is through the manipulation of a sociallyrelevant environmental prime. Priming occurs when a cue or stimulus in the immediate environment activates a concept or mental representation. This activation, in turn, may influence subsequent information processing, as well as behavior (Bargh, Chen, \& Burrows, 1996). Specifically, priming has been shown to influence diverse behaviors such as reaction time (Dijksterhuis, Spears, \& Lepinasse, 2001), memory processes (Pittinsky, Shih, \& Ambady, 2000), and task performance (Steele \& Aronson, 1995).

The Active-Self Account is a theory that recently has been offered in the literature to explain how one's selfconcept interacts with a prime in the social environment. Broadly speaking, this theory suggests that a prime serves to activate parts of the active self-concept that are consistent with the prime (Wheeler, DeMarree, \& Petty, 2007). That is, the prime is believed to increase the accessibility of trait-relevant information that is available as one processes stimuli in the environment. Much of the research that has examined the effect of priming of traits has focused on whether the trait-relevant behavior is expressed. For instance, research has shown that priming the stereotype of the aged led individuals to behave in an elderly manner (Bargh, Chen, \& Burrows, 1996; Kawakami, Young, \& Dovidio, 2012), and participants primed with a high intellect-related cue answered more questions correctly on a general knowledge test (Dijksterhuis et al., 1998). However, far fewer studies have examined whether priming interacts with an endogenous personality construct, such that the expression of the behaviors associated with the personality trait are either magnified or reduced. The purpose of the present study is to address this issue by examining whether personality will differentially affect responses to a help-eliciting social prime.

There is both theoretical and empirical evidence that suggests that most, if not all, Big Five personality traits are associated with helping behavior in some manner. However, one of the dimensions that has been most well documented in this regard is Conscientiousness, and thus in the present study we chose to focus on this trait. The trait of Conscientiousness is associated with behaviors such as a sense of duty, dependability, and diligence when working toward a goal (McCrae \& Costa, 1989), and it has been shown to predict such varied prosocial behaviors as blood donation (Ferguson, 2004) and provision of assistance in a work context (Ladd \& Henry, 2000; Organ \& Ryan, 1995; van Emmerik \& Euwema, 2007). In particular, highly conscientious people often feel a sense of responsibility and moral obligation to their community, and as such, they may be more willing to provide assistance to others (Moon, Livne, \& Marinova, 2013).

To the best of our knowledge there have been no studies that have examined personality and priming in the context of helping behavior. However, recent research has demonstrated that personality can moderate the effect of a prime. As an example, an implicit stress prime had a differential effect on individuals based on their level of Neuroticism. That is, the behavior of individuals high in Neuroticism, as compared to those lower on this dimension, was more pronounced in the priming condition, as evidenced by a greater stress response (Moeller, Robinson, \& Bresin, 2010). Researchers also documented that individuals low in Agreeableness, as compared to those high on this trait, showed greater hostile behavior following exposure to an aggressive prime (Meier, Robinson, \& Wilkowski, 2006). Additionally, extraverts, as compared to introverts, had been shown to display greater sensitivity to positive affect primes (Robinson, Moeller, \& Ode, 2010). These findings demonstrate that one's reaction to a situational prime is influenced by personality.

Given the literature reviewed above regarding Conscientiousness and prosocial behavior, along with the recent findings that demonstrate that personality can moderate the influence of a prime, it is reasonable to predict that the personality trait of Conscientiousness could serve as an important moderator of a help-eliciting prime. The help-eliciting prime that was used in this study asked participants to write about the thoughts that come to mind with regard to a super-hero. This help-eliciting prime has been successfully used by other researchers to prime helping responses (Nelson \& Norton, 2005). We postulate that when highly conscientious individuals engage in this task, the activation of memories associated with a super-hero will also cue their own self-concept with regard to characteristics that they might share with a super-hero. In particular, individuals who are highly conscientious tend to feel a sense of duty and moral obligation to assist others, and as such, these ideas should be well represented in their schemas concerning helping. Thus, when presented with a scenario in which they are asked whether they would honor a commitment to help a friend, even if they have to forgo a highly desired activity, it is predicted that highly conscientiousness individuals would be more like to report that they would do so, as compared to people lower in conscientiousness (Hypothesis 1). It is also predicted that this tendency would be magnified when individuals are in the presence of the help-eliciting prime, as the notions of one's 
moral obligation would be more strongly activated. Therefore, it is predicated those individuals who are highly conscientious and are in the prime condition would report the greatest helping (Hypothesis 2). Finally, to determine whether highly conscientious individuals, as compared to those scoring low on this trait, did respond differently with respect to the help-eliciting prime, a textual analysis of participants' descriptions of the super-hero was conducted. In particular, it was predicted that individuals high in Conscientiousness, as compared to those low on this dimension, would be more likely to describe the super-hero by using words involving the super-hero's sense of ethical responsibility to the community (Ethical Responsibility), along with the importance of helping others (Helping) (Hypothesis 3). Finally, to ensure that the trait of Conscientious doesn't simply influence individuals to write more verbosely on all characteristics of a super-hero, rather than those most similar to Conscientiousness, a final predication was made. That is, given that the trait of Conscientiousness is silent with respect to one's appearance, we hypothesize that there will be no difference between those high and low in Conscientiousness with regard to the use of words describing the physical attributes of the super-hero (Hypothesis 4).

\section{Method}

\subsection{Participants}

Participants $(N=203)$ were recruited from a university located in the southeastern region of the United States. Subjects participated in the study for course credit. Females constituted $71 \%$ of the sample. The participants were primarily White (86\%), although both Blacks and Hispanics were represented (10\%), with the remaining 4\% listing “Other.” Participants ranged in age from 18 to 20 (83\%), 21 to 23 (11.5\%), and 24 or older (5.5\%). Of the original sample, five participants did not participate in both sessions of data collection, and thus were lost to attrition. These participants did not differ significantly from the overall sample with regard to the demographic characteristics of age, gender, or ethnicity.

\subsection{Materials}

The following questionnaires were administered to the research participants: The NEO-FFI Personality Inventory (NEO; Costa \& McCrae, 1992), The Marlowe-Crowne Social Desirability Scale (MCSD; Reynolds, 1982), and a scenario that was developed to assess prosocial behavior. The NEO Personality Inventory contains 60 items that participants respond to by choosing from a 5-point Likert scale which ranges from strongly agree to strongly disagree. The scale is made up of five factors, but for the purposes of the present study only the Conscientiousness subscale was examined. In the present study the alpha level of this trait was acceptable: $\alpha=.833$. The MCSD was used to assess the tendency that subjects might have to portray themselves in an overly socially appropriate or nondeviant manner. This inventory contains 13 items that participants respond to by indicating whether the statement is true or false. Scores range from 0 to 13, with higher scores indicating a stronger social desirability response. The internal consistency for the MCSDS was .907 in the present study. Regarding the helping measure, participants read a short vignette that assessed helping behavior. To conceal the purpose of the study this vignette was bracketed by other scenarios that were unrelated to helping. Regarding the helping scenario, participants were asked to image that a close friend was in the hospital recovering from surgery. Further, they had promised to visit this friend after their surgery, but at the last minute they were given tickets to see a performer they greatly admired at a concert on the same night. After reading the vignette, participants were asked to indicate using a 5-point response format (very unlikely to very likely) how likely it was that they would forgo attending the concert to keep their promise and help their friend.

\subsection{Procedure}

To ensure that the assessment of personality did not influence participants' responses to the priming manipulation, the study was divided into two parts which were separated by a one-week interval. However, participants were led to believe that they were participating in two separate studies. At the beginning of the first session, participants were told to write their names on a sealed envelope, which contained a subject identification number. These envelopes were used to ensure participants retained their identification number for the second study. They were told this was necessary so that their experimental credit could be accurately recorded. Participants were then given a packet that contained a series of scales. Participants first responded to the personality questionnaire 
and then completed the Marlowe-Crowne Social Desirability Scale. Other questionnaires were also administered, but are not relevant to the goals of this study. After completing these surveys, participants submitted their packets and quietly exited the experimental room.

After a one week delay, small groups of participants were randomly assigned to one of the following conditions: the Superhero condition or a Control condition. In the Superhero condition, participants were asked to think of a superhero and list the behaviors, values, lifestyle, and appearance associated with a superhero. Given that super-heros are typically associated with helping others, this procedure is believed to make more accessible help-relevant information and it has been shown to effectively prime helping behavior (Nelson \& Norton, 2005). For the Control condition, participants were given similar verbal and written instructions, except they were asked to describe the characteristics of a dorm room. All groups were given 5-minutes to complete the priming activity.

After completing the priming activity, participants were asked to respond to several scenarios, one of which served as the criterion measure of helping. Upon completion of the helping scenario, participants were asked to answer questions that probed as to whether they were aware of the purpose of the experiment. Findings indicated that all participants were naïve as to the hypotheses of the study. Participants were given unlimited time to complete both of these activities.

\subsection{Data Analysis}

The written responses to the Super-hero prime were coded by two independent reviewers who were naïve to the respondent's level of Conscientiousness. Words coded were separated into three categories: The Super-hero's ethical responsibility to act (Ethics: duty, ethics, moral, obligation, responsibility), the Super-hero's role in helping others (Helping: altruism, helping, giving, caring for), and the Super-hero's physical characteristics (Physical attributes: muscular, attractive, fly, fast). A sample of one subject's written response, along with the scoring, is included in the Appendix. Analyses of the two scorers' ratings using Cohen's Kappa indicated a very high level of agreement across these coded categories, $k=.875, k=.816$, and $k=.825$, respectively.

Prior to hypothesis testing, variables were screened for normality and those variables with high standardized skewness values (defined as $-3 \geq z \geq 3$ ) were transformed using a logarithmic procedure. The only variable that required transformation was Social Desirability.

Given the aims of the study, an ANCOVA procedure was used to test the first two hypotheses of the study. The covariates in this analysis included the variables of social desirability and gender. Conscientiousness was split at the median to examine its interaction with the Priming variable on self-reported helping. Regarding the third hypothesis, Chi-square analyses were conducted to determine whether individuals high and low in Conscientiousness would differ in their verbal behavior when describing the super-hero. Specifically, these analyses tested whether or not participants described the super-hero using the following descriptor categories: Ethical Responsibility and Helping. A Chi-square analysis also was conducted to determine if those high and low in Conscientiousness would differ in their use of words to describe the physical characteristics of the super-hero.

\section{Results}

An ANCOVA analysis revealed a significant main effect for Conscientiousness, such that those high on this trait reported greater helping $(F(1,184)=5.67, p=.03)$. Analyses also showed a significant interaction effect between Conscientiousness and the Prime, such that those high in Conscientiousness in the help-eliciting prime condition reported the highest level of helping $(F(1,184)=5.99, p=.03$; see Figure 1).

Lastly, Chi-square analyses showed that highly Conscientious individuals were more likely to use words associated with one's ethical responsibility to act when describing the super-hero $\chi^{2}(1)=8.13, p=.002$; see Figure 2). A marginal effect was found with regard to whether participants used words associated with helping when describing the super-hero $\left(\chi^{2}(1)=2.40, p=.06\right.$ ). Individuals high in Conscientiousness were more likely to use words associated with helping. No significant effect was found between those low and high in Conscientiousness with regard to the description of the super-hero's physical attributes $(p=.68)$.

\section{Discussion}

The theory of interactionism enjoys widespread acceptance in the field of personality and social psychology 


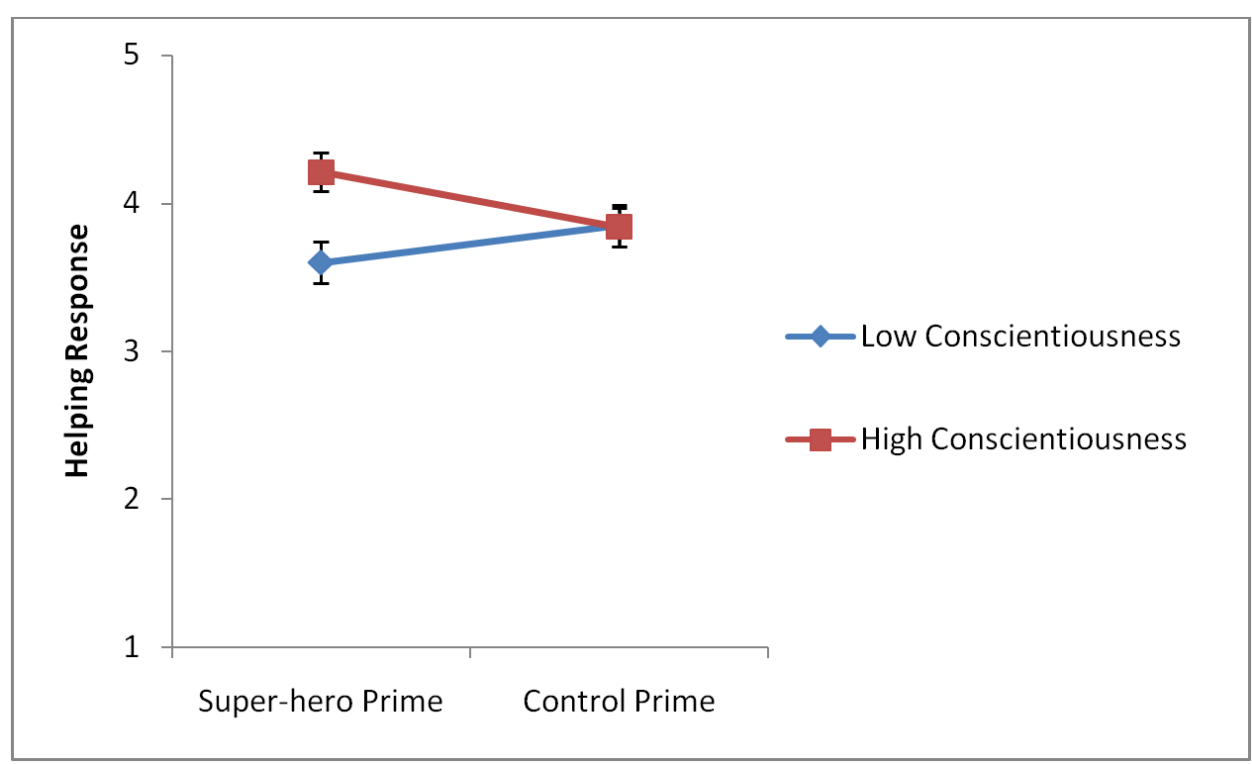

Figure 1. Conscientiousness and the prime interact to influence helping responses.

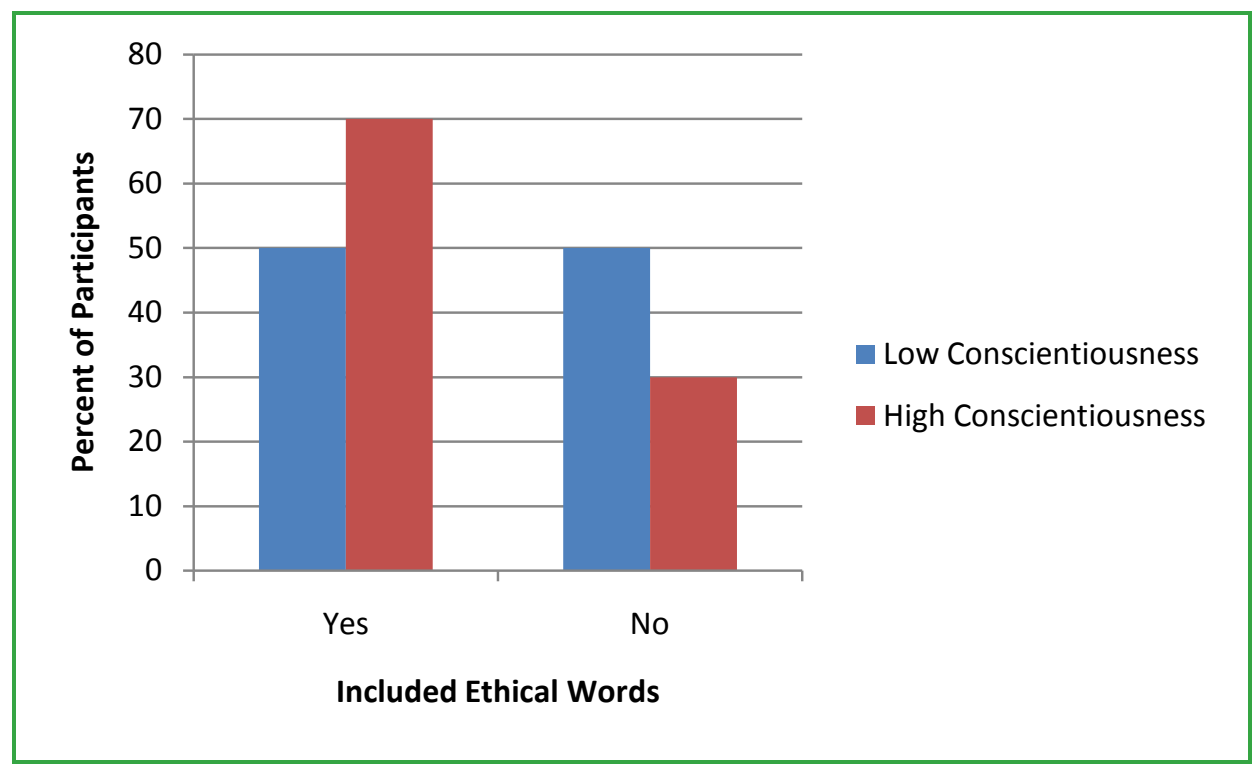

Figure 2. Percent of participants who wrote about the super-hero's ethical responsibility to help across level of Conscientiousness.

(Blass, 1991). However, this support is based in large part on the logical nature of the theory, rather than on an expansive set of empirical findings. With regard to the present study, we provide a viable protocol that can be used to study how personality may interact with situational variables. Findings from this study demonstrate that the effect of a situational prime on helping behavior is dependent, at least in part, on one's personality.

As predicted, results showed that highly conscientious individuals, as compared to those low on this dimension, responded differently to the help-eliciting prime regarding the descriptions of the super-hero that they generated. Specifically, they were more likely to include in their descriptions words that addressed the sense of responsibility and moral obligation that a super-hero has to his or her community. Albeit, not as strong of an effect, highly conscientious individuals also were more likely to include in their descriptions of the super-hero the role that he or she played in helping others. Finally, to test whether Conscientious individuals simply are more verbose when responding to a prime in general, we examined whether differences would emerge regarding the in- 
clusion of descriptions of the physical attributes of the super-hero. This analysis revealed that highly conscientious individuals were no more likely to discuss the super-hero's appearance than those lower on this trait.

After responding to the prime, participants were asked to read over several vignettes, one of which asked whether they would forgo a highly coveted opportunity in order to keep an important promise that they made to help a friend. Analyses revealed a main effect for Conscientiousness, such that highly conscientious individuals were more likely to report that they would keep their promise and help their friend. These findings are quite consistent with the core features of Conscientiousness. Namely, individuals who are high in Conscientiousness would be unwilling to retract a promise made to their friend due to their strong sense of responsibility and duty to keep the commitments that they have made (McCrae \& Costa, 1989). Additionally, and as predicted, a significant interaction effect was found such that those in the help-eliciting prime condition who were higher in Conscientiousness reported the greatest level of helping (see Figure 1). Thus, the tendency to engage in self-sacrifice and assist others can be magnified in highly conscientious individuals when they are in the presence of an appropriate situational prime. Interestingly, individuals who were in the help-eliciting prime condition who scored low in Conscientiousness reported the lowest level of assistance of any group in the study (see Figure 1). So, in this particular case, the Superhero prime appears to have actually reduced reports of helping for this group. In explaining this finding, it is important to remember that while it is true that priming typically promotes behavioral assimilation and expression of the cued category, depending upon the characteristics of the prime, behavior can be incongruent with, or even opposite of, the prime. This process, known as a Contrast Effect, may arise when an exemplar (i.e., a specific member of the category) serves as the prime, rather than a general descriptor of the category that is being cued (Stapel, Koomen, W., \& van der Pligt, J., 1996; Dijksterhuis et al., 1998). When this occurs individuals may compare themselves to the prime, and as a result of this comparison they may recognize, at least at some level, that they are not like the exemplar. As a result, they may express lower levels of the primed behavior. To illustrate, if one is priming intelligence by asking participants to write down characteristics of an intelligent individual, it would be predicted that task performance would be enhanced. However, asking them to write down characteristics of an exemplar of intelligence, such as Albert Einstein, would yield reduced task performance because when cued to think of Albert Einstein, most people would actually feel less intelligent. Similarly, using the exemplar of a Super-hero, rather than asking people to write down characteristics of a helpful person, probably led participants who are the least helpful (i.e., those low in Conscientiousness) to feel particularly unhelpful in comparison to a Super-hero. This, in turn, could lead to lower rates of helping.

To the best of our knowledge, this study provides the first examination of the synergistic effect of a personality trait in the context of a manipulated help-eliciting situational prime. Thus, we believe this work makes an important contribution to the literature. However, as with all studies, improvements can be made that would further strengthen this research. That is, the next set of studies that follow should first replicate this work with a more heterogeneous sample. For example, although the effects of priming should not vary greatly across age, personality traits have been shown to change modestly as one ages (Allemand, Zimprich, \& Hertzog, 2007; Soldz, 1999). As a result, to determine whether the effects found in the current study are robust and do not appreciably vary on the basis of one's age, this work should be conducted with participants across different age groups. Developing additional helping scenarios that assess other forms of prosocial behavior also could add to the generalizability of these findings.

Clearly, further work on this topic is needed before definitive statements can be made regarding the effect of personality and situational cues on helping behavior. However, research in this area could yield useful applications in real-world settings. For instance, non-profit agencies that depend upon a large cadre of volunteers and donors could apply these findings in the development of recruitment and solicitation materials. Specifically, materials that prime exemplars associated with prosocial behavior such as a Super-hero, or even symbols that signify help, such as a red cross, may enhance some forms of helping for some people. As such, agencies may need to better target their solicitations based on characteristics of individuals the organization is attempting to recruit, as traditional helping appeals may be effective for individuals who are high in Conscientiousness, but actually may reduce the tendency to help with individuals who score lower on this dimension.

\section{Conclusion}

In sum, this study examines whether Conscientiousness influences verbal responses to a help-eliciting prime as well as whether it moderated the influence of this type of prime in the prediction of self-reported prosocial be- 
havior. Our results are supportive of an interactionism model as they demonstrate that to effectively understand behavior one must consider both personality and situational factors. As such, we believe this study makes an important contribution to the field in elucidating the complex processes that influence helping behavior.

\section{References}

Allemand, M., Zimprich, D., \& Hertwog, C. (2007). Cross-Sectional Age Differences and Longitudinal Age Changes of Personality in Middle Adulthood and Old Age. Journal of Personality, 75, 323-358. http://dx.doi.org/10.1111/j.1467-6494.2006.00441.x

Bargh, J., Chen, M., \& Burrows, L. (1996). Automaticity of Social Behavior: Direct Effects of Trait Construct and Stereotype Activation on Action. Journal of Personality and Social Psychology, 71, 230-244.

http://dx.doi.org/10.1037/0022-3514.71.2.230

Blass, T. (1991). Understanding Behavior in the Milgram Obedience Experiment: The Role of Personality, Situations, and Their Interactions. Journal of Personality and Social Psychology, 60, 398-413. http://dx.doi.org/10.1037/0022-3514.60.3.398

Costa, P., \& McCrae, R. (1992). Revised NEO Personality Inventory (NEO PI-R) and NEO Five-Factor Inventory (NEO-FFI) Professional Manual. Odessa, FL: Psychological Assessment Resources.

Dijksterhuis, A., Spears, R., \& Lepinasse, V. (2001). Reflecting and Deflecting Stereotypes: Assimilation and Contrast in Impression Formation and Automatic Behavior. Journal of Experimental Social Psychology, 37, 286-299. http://dx.doi.org/10.1006/jesp.2000.1449

Dijksterhuis, A., Spears, R., Postmes, T., Stapel, K., Koomen, W., van Knippenberg, A., \& Scheepers, D. (1998). Seeing One Thing and Doing Another: Contrast Effects in Automatic Behavior. Journal of Personality and Social Psychology, 75, 862871. http://dx.doi.org/10.1037/0022-3514.75.4.862

Ekehammer, B. (1974). Interactionism in Personality from a Historical Perspective. Psychological Bulletin, 81, $1026-1048$. http://dx.doi.org/10.1037/h0037457

Endler, N., \& Magnusson, D. (1976). Interactional Psychology and Personality. Washington, DC: Hemisphere.

Ferguson, E. (2004). Conscientiousness, Emotional Stability, Perceived Control and the Frequency, Recent, Rate and Years of Blood Donor Behavior. British Journal of Health Psychology, 9, 293-314. http://dx.doi.org/10.1348/1359107041557011

Kawakami, K., Young, H., \& Dovidio, J. (2012). Automatic Stereotyping: Category, Trait, and Behavioral Activations. Personality and Social Psychology Review, 1, 3-15.

Ladd, D., \& Henry, R. (2000). Helping Coworkers and Helping the Organization: The Role of Support Perceptions, Exchange Ideology, and Conscientiousness. Journal of Applied Social Psychology, 30, 2028-2049. http://dx.doi.org/10.1111/j.1559-1816.2000.tb02422.x

McCrae, R., \& Costa, P. (1989). The NEO Five Factor Inventory. Odessa, FL: Psychological Assessment Resources.

Meier, B., Robinson, M., \& Wilkowski, B. (2006). Turning the Other Cheek: Agreeableness and the Regulation of Aggression-Related Primes. Psychological Science, 17, 136-142. http://dx.doi.org/10.1111/j.1467-9280.2006.01676.x

Moeller, S., Robinson, M., \& Bresin, K. (2010). Integrating Trait and Social-Cognitive Views of Personality: Neuroticism, Implicit Stress Priming, and Neuroticism-Outcome Relationships. Personality and Social Psychology Bulletin, 36, 677689. http://dx.doi.org/10.1177/0146167210367487

Moon, H., Livne, E., \& Marinova, S. (2013). Understanding the Independent Influence of Duty and Achievement Striving When Predicting the Relationship between Conscientiousness and Organizational Cultural Profiles and Helping Behaviors. Journal of Personality Assessment, 95, 225-232. http://dx.doi.org/10.1080/00223891.2012.740539

Nelson, L., \& Norton, M. (2005). From Student to Superhero: Situational Primes Shape Future Helping. Journal of Experimental Social Psychology, 41, 423-430. http://dx.doi.org/10.1016/j.jesp.2004.08.003

Organ, D., \& Ryan, K. (1995). A Meta-Analytic Review of Attitudinal and Dispositional Predictors of Organizational Citizenship Behavior. Personnel Psychology, 35, 1-62.

Pittinsky, T., Shih, M., \& Ambady, N. (2000). Will a Category Cue Affect you? Category Cues, Positive Stereotypes and Reviewer Recall for Applicants. Social Psychology of Education, 4, 53-65. http://dx.doi.org/10.1023/A:1009656413789

Reynolds, W. (1982). Development of Reliable and Valid Short Forms of the Marlowe-Crowne Social Desirability Scale. Journal of Clinical Psychology, 38, 119-125.

http://dx.doi.org/10.1002/1097-4679(198201)38:1<119::AID-JCLP2270380118>3.0.CO;2-I

Robinson, M., Moeller, S., \& Ode, S. (2010). Extraversion and Reward-Related Processing: Probing Incentive Motivation in Affective Priming Tasks. Emotion, 10, 615-626. http://dx.doi.org/10.1037/a0019173 
Soldz, S., \& Vaillant, G. E. (1999). The Big Five Personality Traits and the Life Course: A 45-Year Longitudinal Study. Journal of Research in Personality, 33, 208-232. http://dx.doi.org/10.1006/jrpe.1999.2243

Stapel, D., Koomen, W., \& van der Plight, J. (1996). The Referents of Trait Inferences: The Impact of Trait Concepts versus Actor-Trail Links on Subsequent Judgments. Journal of Personality and Social Psychology, 70, 437-450. http://dx.doi.org/10.1037/0022-3514.70.3.437

Steele, C., \& Aronson, J. (1995). Stereotype Threat and the Intellectual Test Performance of African Americans. Journal of Personality and Social Psychology, 69, 797-811. http://dx.doi.org/10.1037/0022-3514.69.5.797

vanEmmerik, I., \& Euwema, M. (2007). Who Is Offering a Helping Hand? Associations between Personality and OCBs, and the Moderating Role of Team Leader Effectiveness. Journal of Managerial Psychology, 22, 530-548. http://dx.doi.org/10.1108/02683940710778422

Wheeler, S., DeMarree, K., \& Petty, R. (2007). Understanding the Role of the Self in Prime-to-Behavior Effects: The Active-Self Account. Personality and Social Psychology Review, 11, 234-261. http://dx.doi.org/10.1177/1088868307302223 
Scientific Research Publishing (SCIRP) is one of the largest Open Access journal publishers. It is currently publishing more than 200 open access, online, peer-reviewed journals covering a wide range of academic disciplines. SCIRP serves the worldwide academic communities and contributes to the progress and application of science with its publication.

Other selected journals from SCIRP are listed as below. Submit your manuscript to us via either submit@scirp.org or Online Submission Portal.
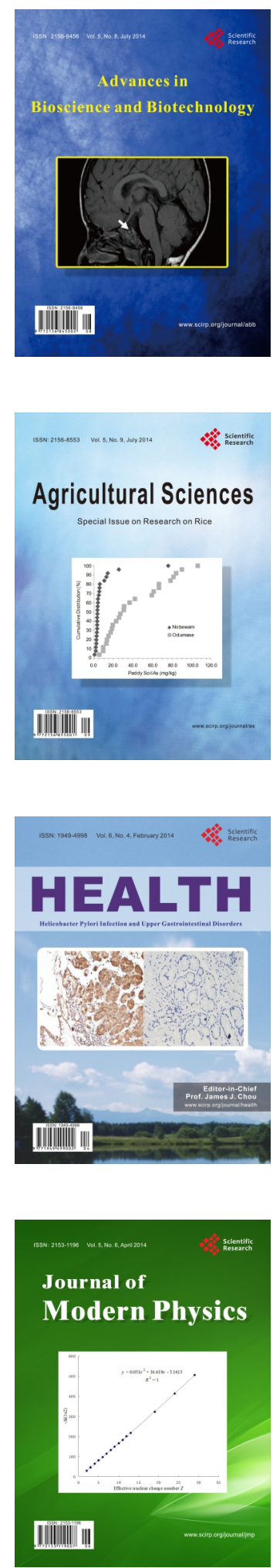
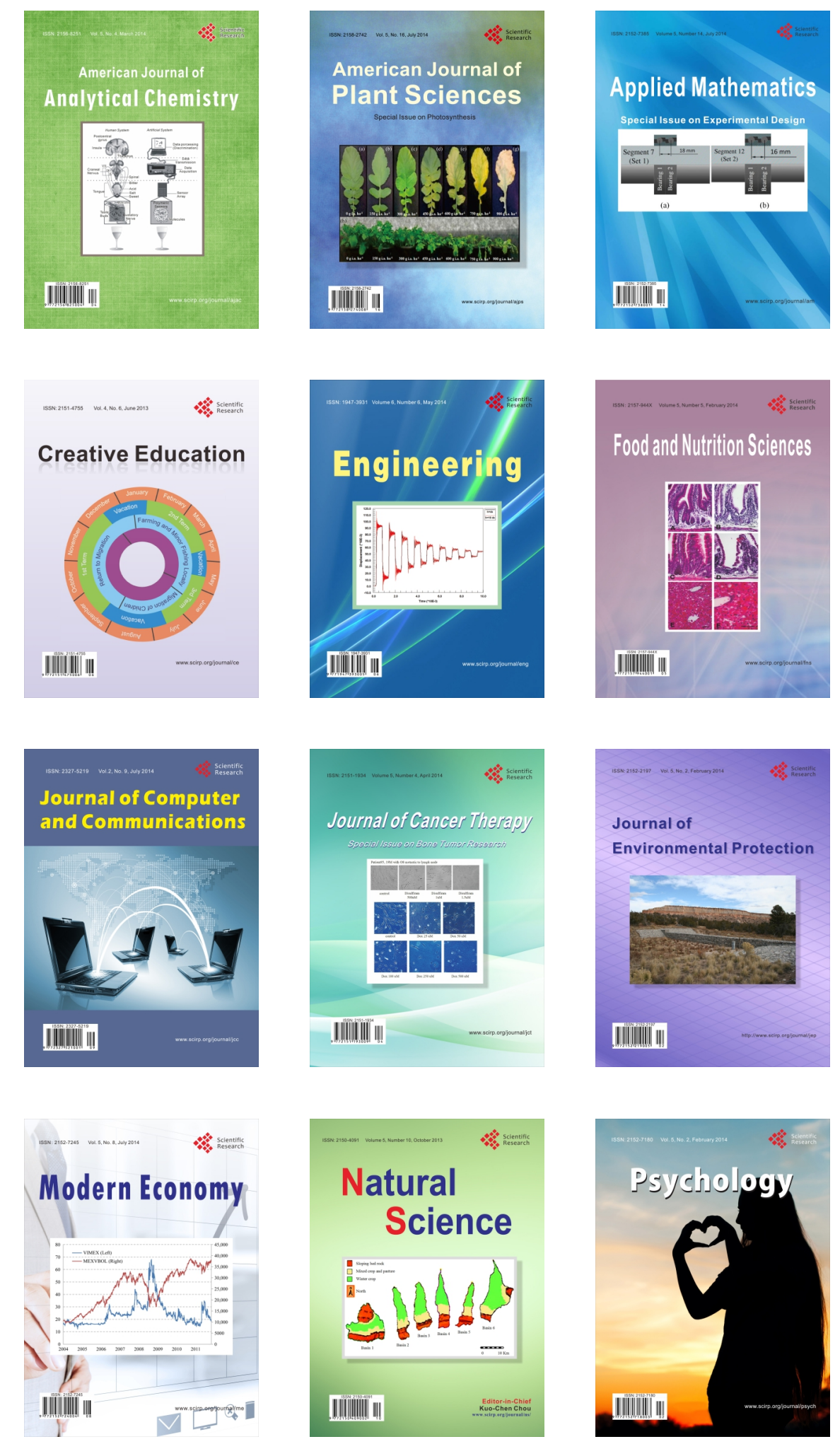